\title{
Emerging trends in retail pricing practice: Implications for research
}

Michael Levy

Charles Clarke Reynolds Professor of Marketing, Babson College

Wellesley

Dhruv Grewal

Toyota Chair of e-Commerce and Electronic

Business and Professor of Marketing, Babson College

Wellesley

This paper was previously published in the Journal of Retailing

The authors thank Bill Bearden and David Bell for their thoughtful comments on a previous draft of this manuscript.

\author{
Praveen Kopalle \\ Associate Professor, Tuck School of Business, \\ Dartmouth College \\ Hanover
}

James Hess

Bauer Professor of Marketing Science

University of Houston

\section{ABSTRACT}

This article represents the first of several editorials to appear in the Journal of Retailing designed to examine the nexus between retail practice and research, with the goal of stimulating further research. This essay on emerging trends in pricing discusses recent advances in retail pricing optimization. We begin with a review of how retailers typically make pricing decisions using time-honored heuristics and attempt to infer the optimal decisions. However, current methods are sub-optimal because they do not consider the effects of advertising, I competition, substitute products, or complementary products on sales. Most fail to take 1 into account how price elasticity changes over time, particularly for fashion merchandise, or how market segments react differentially to price changes. In addition, many retailers find it difficult to know how to price merchandise when their suppliers offer temporary 'deals'. They are also generally unaware of how their pricing strategy influences their overall image. I As these issues demonstrate, optimal pricing is not a static problem. Retailers must be able 1 to react quickly to changes in the environment or sales patterns. This paper also provides examples of the more sophisticated pricing techniques that are currently being tested in practice. Finally, we conclude with a discussion of the critical components that must be incorporated into retail pricing.

\section{INTRODUCTION}

Most retailers do not use price as a basis for achieving a sustainable competitive advantage, because it is too easy for competitors to copy a low-price strategy and very few retailers can be successful with a low cost-low price strategy, such as Wal-Mart's. Price can be used strategically, however, even if not always to establish the lowest price. For example, when entering a highly competitive market, a retailer could sacrifice significant profits to build market share. To pursue such a strategy may be perilous, however, unless it can be implemented properly. Retail managers must consider carefully certain key factors, such as the customers, competition, and government regulations (Grewal and Compeau, 1999; Monroe, 2003) and then develop, implement, and evaluate the appropriate pricing strategy and tactics.

American retailers are losing more than $\$ 200$ billion a year due to markdowns, or dynamic price cuts over time (Top of the 
Net, 2002). ${ }^{1}$ Markdowns as a percentage of U.S. retail sales represented 8\% in 1971 and $35 \%$ in 1996; according to an STS Market Research study, 78\% of all apparel sold currently by national chains, such as JCPenney, Sears, and Kohl's is marked down. ${ }^{2}$ Thus, markdowns are clearly a substantial and important aspect of today's retail landscape. Retailers and their customers have come to expect prices that are below the manufacturer's suggested retail price (MSRP). For more than 20 years, manufacturers, particularly in the grocery industry, have fueled this markdown mania by tempting retailers with special temporary price reductions coupled with promotions. Retailers of all kinds use these frequent price promotions to lure customers to their stores and, in turn, customers have come to recognize the retail pattern of marking down merchandise after a prespecified period of time and, therefore, wait until goods are on sale. These practices have had a deleterious effect on profits and contributed to the demise of many smaller retailers.

Until recently, retailers typically based their initial pricing and subsequent markdown decisions on arbitrary rules that they believed had worked well in the past. Fortunately, a few specialized firms recently have developed software packages to assist retailers in making these important pricing decisions. These packages are just part of an assortment of programs known as 'merchandise optimization techniques' (Friend and Walker, 2001).

Merchandise optimization, which can have a direct, profound impact on the bottom line, is all the rage in retailing circles these days. It is well represented in the trade press and most retailing conferences devote significant time to the topic. Some of the largest retailers in the country (e.g. Home Depot, JCPenney) have invested millions of dollars in sophisticated merchandise optimization software. The Canadian apparel retailer, Northern Group Retail Ltd. started using ProfitLogic Price Optimization (Cambridge, Mass.) software and, in a test, was able to generate $\$ 60,000$ of additional gross margin dollars on one stock keeping unit (SKU) by holding its outerwear at full price, though prior experience indicated that it should have reduced the cost by 30\% (Retail Systems Alert 2003).

Similarly, price and promotion optimization software, developed by KhiMetrics (Scottsdale, Ariz.), has been implemented successfully by top retailers in the grocery, drug, electronics, specialty, and mass merchandising fields. Results from controlled field experiments demonstrate that their solution consistently outperforms that of the control group by increasing profit (1\%-2\% of sales), while maintaining or increasing sales, depending on the retailers' desired goals. Moreover, sales were increased or maintained without any negative effects on total unit movement. Depending on the retailer's margins, the increased profit translates into an overall $5 \%-15 \%$ increase in gross profits and the results were consistent across retail industries.

Retailers have a plethora of decisionmaking tools available that can help them in the following areas: planning assortments, initial pricing, sourcing/ vendor collaboration, buying, allocation of merchandise to stores, promotion, planning replenishment (re-buys), space management (planograms), and markdown pricing. Our goal is to examine emerging pricing practices by retailers and identify pricing research opportunities - across time (for example, initial pricing and markdown pricing decisions), categories, SKUs and customer segments - which, we believe, have strong implications for both research and practice.

1 This research was based on analysis of retail and economic trends reported by the U.S. Census Bureau and the National Retail Federation.

2 lbid. 


\section{TRADITIONAL RETAILER PRICING TECHNIQUES}

Typically, retailers make pricing decisions on the basis of time-honored rules. Retailers using the rules-based approach often apply a fixed percentage markup onto their cost; a keystone markup, for example, results in a markup that is $50 \%$ of the retail price. Rules are applied to markdowns as well. For example, fashion retailers often take a fixed percentage markdown on merchandise that has been in the store for a certain number of weeks, followed by an additional markdown a few weeks later. Another rules-based approach is to price merchandise above, below, or at parity with the competition's pricing.

The maintenance of these pricing rules is consistent with recent trade press articles that suggest that retailers have been slow to adopt sophisticated pricing models (Stores, 2002), have priced products solely on the basis of cost (Retail Industry Report, 2000) and sometimes 'live and die by Excel' by evaluating one brand after another, using 'what-if' analyses that do not incorporate the price impact of one product on another (Forrester Report, 2001). Retailers use a rules-based approach, because it is easy to calculate and implement, particularly in a multi-store chain. Furthermore, pricing with an eye toward the competition helps retailers maintain their price image.

The most fundamental weakness of these rule-based approaches is that none have anything to do with what represents the optimal price or markdown. In the case of the rule-based approach, price is based on what has been done in the past, either the previous year, in the case of fashion merchandise, or the past few weeks, in the case of staple merchandise. In either case, the data are old and usually confounded by promotions. For example, in the absence of price optimization software and demand information about other promotions, if sales increase every year around February 14 and retailers always provide a promotion on that day, those retailers are unable to tease out the impact of their Valentine's Day promotions.

The second problem with the way that retailers price and mark down merchandise is the system-wide character of their decisions. For example, a regional department store chain may take the same markdown on a grouping of sweaters in New England that it does in Texas, though the demand for sweaters and the time of their selling seasons may be quite different. In the same way, a supermarket chain might price black beans in Miami, where the majority Latin population creates a huge demand, the same as it does in Tallahassee, where black beans are more of a novelty product.

Most retailers do not find it prudent to use different prices in stores within the same trade area, because customers may become confused or, worse, disillusioned with the integrity of the retailer if they find different prices in contiguous stores. Yet differential pricing in diverse trade areas, particularly if they are geographically isolated, can provide opportunities for increased gross margins and more precise inventory control.

The third problem with rule-based approaches is that customers learn from past experience when merchandise will be placed on sale. Such sale-savvy customers play havoc with retailers' gross margins, because they wait for sales to buy.

Given these problems, a natural question is why retailers continue to use rule-based approaches. One retailer put it this way (Hall, Kopalle, and Krishna, 2004, p. 30):

'Many times, we simply don't have the data to figure out the complex interactions among the brands and when we do have the data, we either don't have the time to analyze it fully or we don't have the expertise to conduct an in-depth analysis. It is far easier for us to go just with some markup rule or, at best, look at each brand separately by considering how much of a lift we would get if we reduce the price by a certain amount.' 
Although some retailers can experiment with new items to determine profitmaximizing prices, this approach is impractical for most retailers, because they have too many items to consider. In addition, experiments simply are not timely. By the time the results come in, the item could be in another stage of its life-cycle. Experimentation could, however, work for a chain, such as the Cheesecake Factory, when it wants to try a new menu item. The restaurant could offer the item at different prices in different markets to determine which price is the most profitable.

\section{TWO DISPARATE PRICING PROBLEMS: FASHION AND STAPLE MERCHANDISE}

Although there are many types of merchandise, from an inventorymanagement perspective, most SKUs fit into one of two categories: fashion or staples. Fashion is a category of merchandise that typically lasts 8-12 weeks and sales vary dramatically from one season to the next. Within the fashion category, a specific style or SKU sells for one season or less. Although the life-cycle of a typical fashion item is much shorter than that of a staple, its lifespan depends on the category and the target market. For example, double-breasted suits for men or certain popular interior decorating colors represent fashions whose life-cycle may last several years. In contrast, trendy fashions, such as see-through track shoes, may last for only a short season. ${ }^{3}$

Items in the staple merchandise category (also called 'basic merchandise' or 'fastmoving consumer goods') are in continuous demand during an extended period of time. Most merchandise in grocery and drug stores, as well as housewares, hosiery, basic blue jeans and women's intimate apparel in specialty and department stores, are considered staple merchandise. ${ }^{4}$

We depict a representation of the life-cycle for fashion and staple goods merchandise in Figure 1. There are several similarities between the two graphs. Both lines have 'spikes', which represent increases in sales - usually caused by promotions.

Figure 1: Demand Curves for Staple and Fashion Goods

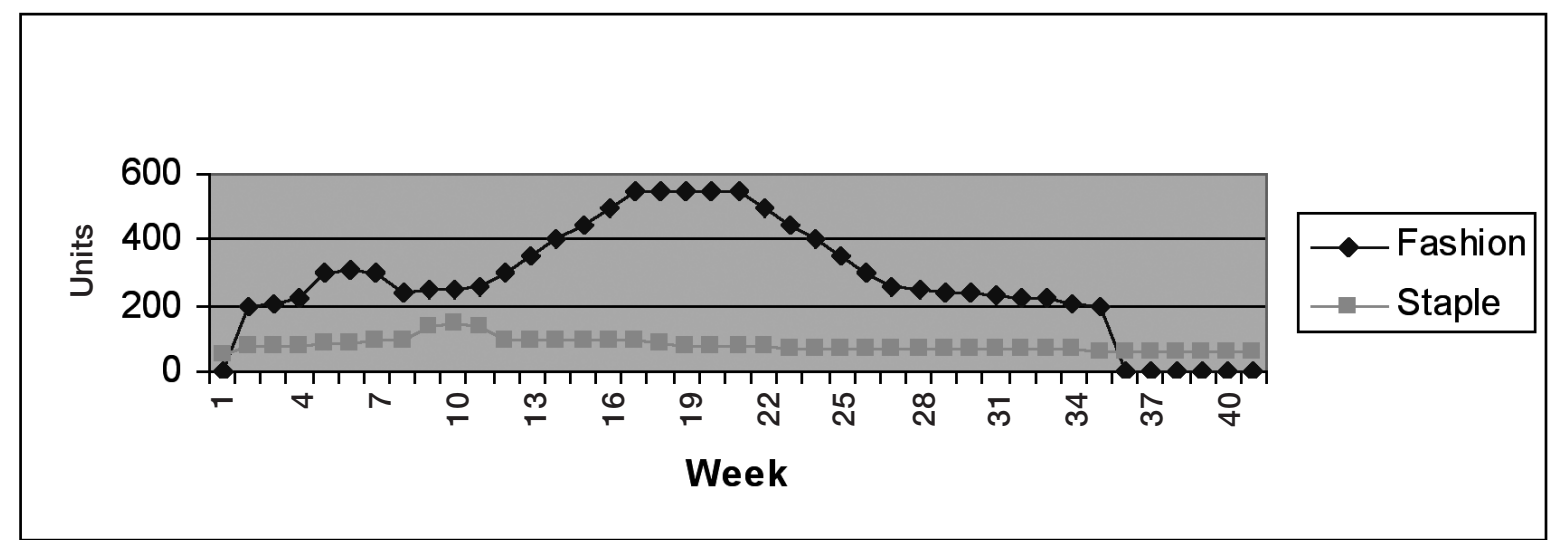

3 One firm that specializes in pricing optimization for fashion merchandise is ProfitLogic (profitlogic. com).

4 Firms that specialize in pricing optimization for staple merchandise include KhiMetrics (khimetrics.com) and DemandTec (demandtec.com). 
After the promotion, the level of sales settles down to somewhere near its previous level. However, there are also important differences in the life-cycles of fashions and staples in Figure 1. Firstly, the fashion curve is similar in form to a 'normal' or bell-shaped curve, in which sales start at zero, increase over a particular season and end at zero. The staple line, by contrast, remains relatively flat, though it may veer up or down, depending on the general trend for the SKU and the season. Secondly, the demand line for staple merchandise never approaches zero. Unlike fashions, staples continue selling, at least over a reasonable planning horizon.

The systems designed to optimize price for both fashion and staple goods are complicated, but for different reasons. For fashion goods, the objective is to maximize the profits for the item or category and, at the same time, price the merchandise so that inventory approaches zero at the end of the fashion cycle, because at that time, it is out of style and has little or no value in the marketplace. That is, if a store has a lot of sweaters left over in January, it must aggressively mark them down to ensure that they are gone in time for the arrival of spring merchandise.

Because staple merchandise continues to sell throughout the year, staple retailers do not need to consider the complication of pricing to be out of stock on a certain date. However, the staple merchandise optimization problem is complicated due to the number of potential decisions that must be made. Pricing decisions can be made at the SKU level for staple merchandise and retailers must take into consideration the effect that the price of one SKU has on another or the effect one category of SKUs has on another category. Therefore, the sheer size of the optimization problem for staple merchandise can be daunting.

Although the differences between pricing optimization systems for staple and fashion merchandise appear to be substantial and, though, software vendors approach the problems with a variety of analytical techniques, the underlying principle of maximizing profits by analyzing price elasticities remains the same.

\section{CRITICAL COMPONENTS TO BE INCORPORATED INTO RETAIL PRICING}

Retailers are interested in maximizing their profits. To do so, they need to understand how to price their merchandise optimally. What does optimal price really mean? It is the price at which profits are maximized by item or group of items. Of course, this process is not as easy as it sounds. For example, by maximizing the profits of one item by setting its 'optimal' price, the retailer may sacrifice profits on another item whose demand correlates with the first item. To illustrate, if a retailer reduces the price of an 8-ounce can of Hunt's tomato sauce, the demand for the 12-ounce can might decrease.

Next, we discuss this and six other factors that must be taken into consideration to determine optimal prices. To summarize, these factors are as follows:

1. Price sensitivity, or how demand for an SKU changes with its price; for fashion merchandise, how does price sensitivity change over time? (e.g. a markdown for a sweater in May may not create the same sales lift as the same markdown would in January.)

2. Substitution effects, namely, how demand for an SKU changes with the price of a competing SKU.

3. Dynamic effect of price promotions over time, or how changing prices today affects tomorrow's demand.

4. Segment-based pricing, which investigates how prices vary across different markets/customer segments.

5. Cross-category effects, or accounting for demand complementarities across categories.

6. Retailer costs (wholesale prices and trade deals) and discounts.

7. To what extent competition at the retail level influences retail prices. 


\section{Price sensitivity effects}

At the most basic level, to determine an optimal initial or markdown price, the retailer must assess its own-price elasticities (derived from demand curves, which are usually non-linear) to measure how sensitive demand is to price for a given item over a period of time. Although price elasticities generally have a negative sign, to suggest that an increase in price usually results in a decrease in demand, in some situations, however, a decrease in price can lead to a perception of lower quality, which thus decreases demand. Such pricequality inferences are well documented in behavioral pricing research (e.g. Dodds, Monroe, and Grewal, 1991). In addition, the role played by quality signals (e.g. price marching guarantees, warranties, store reputation and brand image) must be incorporated (Estelami, Grewal, and Roggeveen, 2004; Kukar-Kinney and Walters, 2003; Miyazaki, Grewal and Goodstein, 2004; Srivastava and Lurie, 2004).

Estimating price elasticities for fashion merchandise is more complex, because fashions are not stable over the course of the season. A price reduction prior to Christmas, for example, will cause a higher sales spike than if the same reduction were introduced in September. Furthermore, the joint effects of advertising and price promotions on price sensitivity and demand must be incorporated explicitly (Kalra and Goodstein, 1998; Sethuraman and Tellis, 2002).

\section{Substitution effects}

At the general level, the substitution effects - cross-price elasticities or cross-price effects - of a brand refer to the effect of the change in the price of an SKU on the demand for a competing SKU (Besanko, Dubé and Gupta, 2004). Bell, Chiang, and Padmanabhan (1999) note that almost $75 \%$ of consumer response to promotions is due to brand switching. Hence, if an SKU can steal market share from a competing
SKU because of its price, the retailer should evaluate the relative margins of the two SKUs before lowering the price of the target SKU. Implicit, therefore, in this effect is the interesting observation that 'cross-passthrough' effects exist; that is, changes in the wholesale cost of one SKU can drive changes in the prices of other SKUs. For example, if the wholesale price for SKU ' $\mathrm{A}$ ' is temporarily lowered, it may be optimal for a retailer to 'convert' those customers who normally purchase SKU 'B' to buy SKU ' $A$ ' because of its now higher margin. Such a conversion is determined, in part, by the cross-price effect of SKU ' $\mathrm{A}$ ' on SKU ' $\mathrm{B}$ '. In other words, if SKU ' $A$ ' cannot steal sales from SKU ' $B$ ', it may not be worthwhile to attempt to convert buyers to ' $\mathrm{A}$ '. This complicated effect suggests that retailers should adopt a category management approach to develop a pricing strategy (Basuroy, Mantrala and Walters, 2001; Chen et al, 1999; Chintagunta, 2002; Hall et al, 2004; Zenor, 1994).

\section{Dynamic effects of price promotions}

Retailers often assume that sales (both when there is no promotion [baseline] and when there is a promotion offered) for a given SKU are independent of past pricing activity. Yet recent evidence suggests that sales may be affected by prior discounting activity.

Research in consumer behavior has demonstrated that consumers evaluate retail prices for items relative to certain internal benchmarks or reference prices (Winer, 1986). Some retailer- or manufacturer-supplied information that plays a prominent role in affecting these internal reference prices includes MSRP and retailer-supplied reference prices (e.g. regular price, original price, compare at price). (Lichtenstein and Bearden, 1989; see also reviews by Compeau and Grewal, 1998; Krishna et al, 2002; Urbany, Bearden, and Weilbaker, 1988). Consumers' internal reference prices also can be influenced by past prices, brand promotion frequency 
and the type of store (Kalwani et al, 1990). Therefore, price promotions are likely to affect consumer reference prices or price expectations.

In addition, it is difficult for retailers to understand the differences in the sales lift generated from a promotional vehicle (an advertisement) compared with that attributable to the offer itself (sales price or discount). Ignoring this dynamic can substantially affect the optimal price of an SKU. Furthermore, it is important to understand that different promotions (e.g. discounts, coupons, rebates or bundles) do not only have differential effects (Compeau and Grewal, 1998; Hardesty and Bearden, 2003; Raghubir, 2004), but also result in consumer dynamics such as stockpiling and purchase deceleration (Neslin, 2002).

Consider the following example (Kopalle, Mela and Marsh, 1999): a few years ago, a major discount store chain used sales promotions relatively infrequently. Its offdiscount (baseline) sales were moderate and consumer response to sales promotions was good. Observing the promotional response, the retailer decided to increase sales promotions, which led to a decrease in baseline sales. Believing that the additional sales promotions were successful, the retailer added even more. Eventually, the retailer started offering special promotions almost every week, and its management wondered why profitability was so low, since the large incremental demand over the baseline indicated that the promotions were working so well.

Why didn't the retailer's management recognize that the increase in sales promotions led to a decrease in baseline sales and that its pricing decisions were sub-optimal? Many retailers have little understanding of how such estimates arise. Clearly, retailers should consider the possibility that increases in the use of price promotions can have long-term negative effects on their baseline sales; in other words, baseline sales could decrease with frequent promotions (Kopalle et al, 1999).
Furthermore, excessive price promotions over time may result in increased customer price elasticity. If these long-term negative effects of promotions on baseline sales and price response are high, retailers should decrease their use of price promotions.

In a large-scale field experiment involving durable goods sold through a direct mail catalog, Anderson and Simester (2004, p.4) find that ' $[\mathrm{d}]$ eeper price discounts in the current period increased future purchases by first-time customers (a positive longrun effect), but reduced future purchases by established customers (a negative longrun effect)'. Most theories of the effect of price promotions, such as purchase acceleration, selection, customer learning and increased deal sensitivity, predict lower future purchases, so their finding regarding first-time buyers is puzzling and should be investigated further.

\section{Segment-based pricing effects}

Consumers in different markets behave differently with regard to their own and cross-price elasticities, as well as how they react to price changes. For example, customers in an upper-income area may be less sensitive to price and the relationship among the prices of various products than those in a less affluent region. By taking these differential factors across markets into consideration, retailers can implement different price and promotion plans across various markets.

A retailer's ability to segment and charge differential pricing may also hinge on the price awareness levels of the consumer segments. For example, prior research has demonstrated that consumers have low levels of price recall and awareness for many products (Binkley and Bejnarowicz, 2003; Dickson and Sawyer, 1990; Mazumdar and Monroe, 1990). Thus, in some categories, retailers may be wasting profits by overdiscounting their merchandise in an effort to appeal to a deal-prone segment, for which a small discount might be sufficient (Inman, McAlister and Hoyer, 1990). 
An emerging retailing strategy - often associated with Internet retailing - is masscustomization, a flexible process designed to provide consumers with a product that is matched to their individually stated needs. Reflect.com, for example, manufactures custom-made cosmetics, but all variants of the customized cosmetics are priced at $\$ 17$, regardless of the color and other variables (e.g. glossy, matte, or a combination thereof, for lipstick). On its website, Land's End offers custom-fit jeans (with more than 100,000 alternatives), all at the same price of $\$ 54$. When retailers mass-customize products, why do they set the same price for all the different variants? Although some retailers have varied their prices (Chen and Iyer, 2002; Shaffer and Zhang, 1995), in many other circumstances, price customization is ignored. In this regard, Stremersch and Tellis (2002) provide a strategic analysis of the optimization of price and product bundles.

\section{Cross-category effects}

Good price and promotion optimization software should be able to take into consideration the effect of one category's price level on another, particularly with regard to substitute and complementary items (Mulhern and Leone, 1991; Walters, 1991). Furthermore, when evaluating the pricing for, say, toothbrushes, a retailer should consider, not only the impact of the toothpaste category on toothbrushes (and vice versa), but also the traffic-building linkages between toothpaste promotions and, for example, bath tissue (Drèze and Hoch, 1998). By considering a complete basket of goods simultaneously, a retailer may be in a better position to optimize its price and promotion levels (Chen et al, 1999).

\section{Retailer costs and discounts}

The wholesale price at which the retailer buys a product has an obvious impact on the optimal prices for the retailer. What is also interesting, however, is the impact of trade deals offered by the manufacturer to the retailer (Hall et al, 2004), which, in turn, give rise to retail discounts and temporary price reductions offered by the retailer to the consumer. Growing evidence indicates that the impact of such retail discounts differs from that of regular price changes (Kopalle etal, 1999), which may reflect a promotional signal effect (Inman and McAlister, 1993). This finding suggests that a retailer should consider its pricing decisions jointly with its promotional discount decisions.

\section{Retail competition}

As highlighted by Lal and Rao's (1997) and Moorthy's (2004) theoretical analyses and Bolton and Shankar's (2003) and Shankar and Bolton's (2004) empirical analyses, one aspect of retail pricing pertains to the impact of competition at the retail level. Two key constraints for retailers in this regard are their lack of knowledge of prices at competing retail stores and the sensitivity of demand to prices in those competing stores.

Firms, such as Information Resources Inc., collect and record pricing and sales data in competing retail stores, which provide researchers with an opportunity to examine pricing and promotion strategies in a holistic fashion. In other words, problems that, previously, have been studied analytically, now may be examined empirically as well. However, there is an additional complexity: a customer's store choice decision is affected, not only by the pricing strategy at a particular store (e.g. everyday low price versus hi-lo), but also by the customer's shopping list for that week (Bell, Ho, and Tang, 1998). Therefore, retailers must anticipate which of the multitude of items in their stores are on a consumer's shopping list.

\section{IMPLEMENTING RETAIL PRICING}

The basics of developing and implementing retail pricing using optimization programs look simple. However, if this were the case, retailers would have done so long ago. To 
develop and implement an effective pricing strategy, analysts must carefully consider several additional factors.

\section{Market factors}

Retailers often must consider market factors other than profit maximization, such as minimum sales and margin requirements, as well as price image. For example, a retailer should be able to specify that it always wants its price to be $5 \%$ lower than that of a specific competitor in certain categories if it hopes to maintain its lowcost provider image. Being able to take price image into consideration is a significant improvement over traditional pricing techniques, because price image explicitly incorporates the relationship between actual price and perceived prices, as well as external competitive factors.

\section{Grouping items}

Retailers of all kinds, but particularly those involved with fast-moving consumer goods, often realign their merchandising strategy to maximize the sales and profits of a category. This process, known as category management, is more difficult than it may appear superficially. In general, a category is an assortment of items that the customer perceives as reasonable substitutes for one another. The determination of what should be included within a category for merchandise and pricing decisions, therefore, is not straightforward and varies significantly across retailers. However, it makes sense to implement pricing and markdown decisions on a category-bycategory basis (Dhar, Hoch, and Kumar, 2001). That is, a specialty store would not want to take a $25 \%$ markdown on blue jeans in January and a 35\% percent markdown on black jeans in February. Instead, it should take the same markdown at the same time so that promotions can be coordinated and customers can understand what is going on readily.

Pricing optimization software should suggest groups of products that could be naturally grouped into categories. This grouping helps the retailer better understand the cannibalization effects of a price promotion on one product type by providing an assessment of the promotion's effects in terms of the decreased sales of the grouped SKUs on one another.

\section{Continual learning}

One of the problems with traditional methods is that analysts set prices on the basis of what has happened in the past. Fashion merchants, for example, often plan a sale at the same time each year using the same percentage discount, regardless of the current inventory position, weather or competitive situation. Staple goods merchants look to the past as well, but their planning horizon is more likely to be the preceding few weeks.

Rather than looking to the distant past, pricing optimization techniques learn from the current environment. Systems designed for both fashion and staple goods incorporate the current environment, but attack the problem somewhat differently. The sales curve for a fashion accessory can be compared to a library of completed curves derived from history. There are anywhere from 20 to 90 such curves, depending on how we define the problem. Recognizing that a fashion retailer must be sold out of inventory at a specific point in time to make room for new merchandise, the software should choose the curve with the best fit, evaluate the price elasticity for that item at different points in time until the 'out date' and run thousands of pricing scenarios to determine the markdown plan that will maximize the retailer's profits.

The problem for staple goods is different because the sales curve is relatively flat. Therefore, the system makes inferences on the basis of other items or product groups. For example, information for an SKU at a given store can be used to make inferences about that SKU at the regional level or for the category of merchandise to which that SKU belongs. By making these inferences, 
researchers can assess the elasticity of an SKU for which the price has never changed.

\section{Psychological price thresholds and reference effects}

Assume that a pricing optimization program recommended a price of $\$ 2.90$ for a staple product, but the retailer, consistent with Anderson and Simester (2003), believes that shoppers in a grocery store do not notice the last digit of a price, so the retailer is free to round the price up to the nearest nine, or $\$ 2.99$. This tactic would increase dollar sales by approximately 3\%, with almost no increase in costs. Pricing optimization programs systematically examine the recommended price $-\$ 2.90$ in this case - and exercise analytical rules to round it up to a higher price that yields more profit, because customers are insensitive to the difference. Consistent with this example, in an analysis of scanner data in 29 categories over an eight-year period, Levy and colleagues (2004) find that small price increases occur more frequently than small price decreases.

A related issue is to incorporate the effects of reference prices - the anchoring levels, or standards that consumers use to compare observed purchase prices of a product - on consumers' internal reference prices and demand (e.g. Blair, Harris and Monroe, 2002; Chandrashekeran and Grewal, 2003; Kalyanaram and Winer, 1995; Kopalle and Lindsey-Mullikin, 2003; Krishna et $a l, 2002)$. If the observed price is greater than the reference price, it is perceived as a loss. In contrast, if the observed price is less than the reference price, it is perceived as a gain. Kopalle, Rao, and Assunção's (1996) results suggest that dynamic (or hilow) pricing is optimal when the positive impact of a gain on sales outweighs the negative impact of a corresponding loss.

\section{Price change costs}

It is expensive for retailers to change prices. The price of finding and changing the cost of an item can range from $\$ 0.25$ to $\$ 0.50$ per item (Levy et al, 1997). A price change cost, therefore, should be built into any optimization model. If the cost of changing the price is greater than the additional revenue projected from the price change, it makes more sense to leave the price alone.

\section{Good data in, good data out}

A multi-billion-dollar retailer can be run on bad, or unrefined, data no more than a rocket-ship can be run on crude oil. The typical problem with retailers, however, is not that they lack sufficient data, rather, they have too much, but not in a useable format!

When it comes to data requirements, retailers are unlike other businesses that make similar decisions. Airlines, for example, have used yield management techniques to make pricing decisions for years. Until recently, however, these sophisticated statistical techniques were unavailable to retailers, which must manage a great deal of data. For example, a typical retail chain might have data about 20,000 SKUs for each of 2,000 stores for 104 weeks, during which time it offers three promotions. At 100 bytes/record, this data set would require approximately 1.2 terabytes of storage capacity.

Not even a great buying team could make sense out of such a mountain of data. To prepare the data for analysis, better systems have algorithms that combine individual SKUs into affinity groups that behave similarly in the marketplace. For example, all six packs of Pepsi would be priced the same, because customers expect it and the manufacturer requires it.

Pricing optimization software also will identify outlier sales points, fill in missing data or smooth out a demand spike that was caused by an aberrant factor, such as weather, a non-recurring promotion or non-recurring competitive action. Most important, it is difficult for retailers to capture lost sales that result from a product being out of stock. If a customer goes to buy 
a 12-ounce bottle of Hunt's ketchup and the store is out of stock, the retailer cannot know if the consumer switched to Heinz, purchased the 8-ounce bottle of Hunt's, or did not make a ketchup purchase at all. Sophisticated algorithms will estimate the lost sale caused by an out-of-stock event and build it into the retailer's demand forecast.

\section{DISCUSSION AND DIRECTIONS FOR FURTHER RESEARCH}

Pricing optimization is currently one of the hottest topics in the retail industry. Much of the basic optimization methodology is well developed in academic circles, particularly in retailer decision-making frameworks (e.g. Tellis and Zufryden, 1995). Yet the compilation of these techniques into a cogent system that can be used on a daily basis by retailers is fairly new. This article has assessed the current state of retail price optimization by examining what should be included and considered in implementing these systems, as well as how they perform relative to other, more traditional, pricing techniques.

We believe this is an interesting, important and appropriate research venue for the Journal of Retailing. Consider the following potential topics:

- Although many retailers recognize the folly of some of their current pricing practices, pricing optimization (and related) software, like any new, major technological investment, is often difficult to justify in terms of cost. Furthermore, there are ongoing costs involved in pricing optimization, as well as significant managerial resistance in some cases. One promising research track might focus on how to help retailers become more comfortable with their decision to adopt such an updated pricing methodology. In particular, researchers should conduct real-life field experiments to compare alternative pricing strategies and show the superiority of the price and promotion optimization methods. With an objective of maximizing category profitability, these experiments would need to consider such factors as category management, retail competition, unit sales, retail prices, wholesale prices and deals, complementary and substitute products, promotional activity and seasonality.

- Pricing optimization can work properly only if SKUs are assigned to categories properly. However, different retailers operationalize this aspect of category management differently. As we might expect, some group similar items into categories, but in other situations, such as in designer fashions and cosmetics, retailers group the categories according to the vendor. Research, therefore, should investigate the following questions:

How do retailers group items into categories? What is the best way to categorize?

- Because pricing optimization makes it possible to use differential price policies in different regions, it is important to examine how consumers react to this method. Although consumers already run into this issue frequently (when buying on the Internet, compared with in stores) and, although grocery stores regularly use differential prices, further research should study how a customer would react if he or she found a sweater on sale at two different prices at two different The Gap stores.

- Profit optimization software enables retailers to determine the optimal price and then round up to squeeze an extra profit out of items that are less pricesensitive. Do consumers recognize these small additional markups? Do they care?

- Although one important goal for retailers is to maximize profits through optimal pricing, there are other, sometimes conflicting, goals to consider. For example, retailers may 
wish to peg their prices to those of their competition or set prices to maintain a certain image. How do these conflicting goals affect their customers and their profits?

- Finally, an emerging trend in retailer strategies is that of frequent shopper programs. Kopalle and Neslin's (2003) analysis suggests that such strategies have the potential to be effective multi-period sales promotion tools when primary demand can expand. It will be interesting to examine how such programs impact retail sales and consumer behavior over time.

These are but a few of the many research initiatives that we hope this article will stimulate.

\section{REFERENCES}

Anderson, E. T. \& Simester, D. I. (2003). 'Mind Your Pricing Cues'. Harvard Business Review (September): 97-103.

Anderson, E. T. \& Simester, D. I. (2004). 'Long-Run Effects of Promotion Depth on New Versus Established Customers: Three Field Studies'. Marketing Science, 23 (1): 4-20.

Basuroy, S., Murali, K. M. \& Walters, R. G. (2001). 'The Impact of Category Management on Retailer Prices and Performance: Theory and Evidence'. Journal of Marketing, 65 (October): 16-32.

Bell, D. R., Chiang, J. \& Padmanabhan, V. (1999). 'The decomposition of Promotional Response: An Empirical Generalization'. Marketing Science, 18 (4): 504-526.

Bell, D. R., Teck-Hua Ho \& Tang, C. S. (1998).'Determining Where to Shop: Fixed and Variable Costs of Shopping'. Journal of Marketing Research, 35 (August): 352-369.

Besanko, D., Dubé J-P. \& Gupta, S. (2004). 'Retail Pass-Through on Competing Brands'. Marketing Science, forthcoming.

Binkley, J. \& Bejnarowicz, J. (2003). 'Consumer Price Awareness in Food
Shopping: The Case of Quantity Surcharges'. Journal of Retailing, 79 (1): 27-35

Blair, E., Harris, J. \& Monroe, K. B. (2002). 'Effects of Shopping Information on Consumers' Responses to Comparative Price Claims'. Journal of Retailing, 78 (3): 175-181.

Bolton, R. N. \& Shankar, V. (2003). 'An Empirically Derived Taxonomy of Retailer Pricing and Promotion Strategies'. Journal of Retailing, 79 (4): 213-224.

Chandrashekaran, R. \& Grewal, D. (2003). 'Assimilation of Advertised Reference Prices: The Moderating Role of Involvement'. Journal of Retailing, 79 (1): 53-62.

Chen, Y., Hess, J. D., Wilcox, R. T. \& Zhang, Z. J. (1999). 'Accounting Profits Versus Marketing Profits: A Relevant Metric for Category Management'. Marketing Science, 18 (3): 208-229.

Chen, Y. \& Iyer, G. (2002). 'Consumer Addressability and Customized Pricing'. Marketing Science, 21 (2): 197-208.

Chintagunta, P. K. (2002). 'Investigating Category Pricing Behavior at a Retail Chain'. Journal of Marketing Research, 39 (May): 141-154.

Compeau, L. D. \& Grewal, D. (1998). 'Comparative Price Advertising: An Integrative Review'. Journal of Public Policy \& Marketing, 17 (Fall): 257-274.

Dhar, S. K., Hoch, S. J. \& Nanda Kumar, N. (2001). 'Effective Category Management Depends on the Role of the Category'. Journal of Retailing, 77 (2): 165-184.

Dickson, P. \& Sawyer, A. (1990). 'The Price Knowledge and Search of Supermarket Shoppers'. Journal of Marketing, 54 (July): 42-53.

Dodds, W. B., Monroe, K.B. \& Grewal, D. (1991). 'The Effects of Price, Brand, and Store Information on Buyers' Product Evaluations'. Journal of Marketing Research, 28 (August): 307-19.

Drèze, X. \& Hoch, S. J. (1998). 'Exploiting the Installed Base Using CrossMerchandizing and Category Destination 
Programs'. International Journal of Research in Marketing, 15 (5): 459-471.

Estelami, H., Grewal, D. \& Roggeveen, A. (2004). 'Determinants of Post-Purchase Consumer Response to Price-Matching Guarantees'. (Working paper).

Forrester Report (2001). 'Retail Revenue Management'. Forrester Research, Inc, 19 (December).

Friend, S. C. \& Walker, P. H. (2001). 'Welcome to the New World of Merchandising'. Harvard Business Review, 79 (November): 133.

Grewal, D. \& Compeau, L. D. (1999). 'Pricing and Public Policy: An Overview and A Research Agenda'. Journal of Public Policy \& Marketing, 18 (Spring): 3-11.

Hall, J. M., Kopalle, P. K. \& Krishna, A. (2004). 'A Category Management Model of Retailer Dynamic Pricing and Ordering Decisions: Normative and Empirical Analyses'. (Working paper, Tuck School of Business, Dartmouth College, Hanover, NH.)

Hardesty, D. M. \& Bearden, W. O. (2003). 'Consumer Evaluations of Different Promotion Types and Price Presentations: The Moderating Role of Promotional Benefit Level'. Journal of Retailing, 79 (1): 17-25.

Inman, J. J. \& McAlister, L. (1993). 'A Retailer Promotion Policy Model Considering Promotion Signal Sensitivity'. Marketing Science, 12 (4): 339-356.

Inman, J. J., McAlister, L. \& Hoyer, W. D. (1990). 'Promotion Signal: Proxy for a Price Cut?'. Journal of Consumer Research, 17 (June): 74-81.

Kalra, A. \& Goodstein, R. C. (1998). 'The Impact of Advertising Positioning Strategies on Consumer Price Sensitivity'. Journal of Marketing Research, 35 (2): 210.

Kalwani, M. U., Chi Kin Yim, Rinne, H. J. \& Sugita, Y. (1990). 'A Price Expectations Model of Consumer Brand Choice'. Journal of Marketing Research, 27 (August): 251-62.

Kalyanaram, G. \& Winer, R. S. (1995). 'Empirical Generalizations from Reference
Price Research'. Marketing Science, 14 (3, Part 2 of 2): G161-G169.

Kopalle, P. K. \& Lindsey-Mullikin, J. (2003). 'The Impact of External Reference Price on Consumer Price Expectations'. Journal of Retailing, 79 (4): 225-236.

Kopalle, P. K. \& Neslin, S. A. (2003). 'The Economic Viability of Frequency Reward Programs in a Strategic Competitive Environment'. Review of Marketing Science, Volume 1.

Kopalle, P. K., Mela, C. F. \& Marsh, L. (1999). 'The Dynamic Effect of Discounting on Sales: Empirical Analysis and Normative Pricing Implications'. Marketing Science, 18 (3): 317-332.

Kopalle, P. K., Rao, A. G. \& Assunção, J. L. (1996). 'Asymmetric Reference Price Effects and Dynamic Pricing Policies'. Marketing Science, 15 (1): 60-85.

Krishna, A., Breisch, R., Lehmann, D. R. \& Yuan, H. (2002). 'A Meta Analysis of the Impact of Price Presentation on Perceived Savings'. Journal of Retailing, 78 (2), 101$\mathrm{xx}$.

Kukar-Kinney, M. \& Walters, R. G. (2003). 'Consumer Perceptions of Refund Depth and Competitive Scope in Price-Matching Guarantees: Effects on Store Patronage'. Journal of Retailing, 79 (3): 153-160.

Lal, R. \& Rao, R. (1997). 'Supermarket Competition: The Case of Every Day Low Pricing'. Marketing Science, 16 (1): 60-80.

Levy, D., Bergen, M., Dutta, S. \& Venable, R. (1997). 'The Magnitude of Menu Costs: Direct Evidence from Large U.S. Supermarket Chains'. Quarterly Journal of Economics, 112 (3): 791-825.

Levy, D., Chen, H., Ray, S. \& Bergen, M. (2004). 'Asymmetric Price Adjustments in the Small: An Implication of Rational Inattention'. Social Science Research Network Working Papers Series (available at http://papers.ssrn.com).

Lichtenstein, D. R. \& Bearden, W. O. (1989). 'Contextual Influences on Perceptions of Merchant-Supplied Reference Prices'. Journal of Consumer Research, 15 (September): 55-66. 
Mazumdar, T. \& Monroe, K. (1990). 'The Effects of Buyers' Intentions to Learn Price Information on Price Encoding'. Journal of Retailing, 66 (1), 15-32.

Miyazaki, A., Grewal, D. \& Goodstein, R. C. (2004).'The Effect of Multiple Extrinsic Cues on Quality Perceptions: A Matter of Consistency'. (Working paper)

Monroe, K. B. (2003). Pricing Making Profitable Decisions, Third Edition, New York: McGraw-Hill Publishing Company.

Moorthy, S. (2004). 'A General Theory of Pass-Through in Channels with Category Management and Retail Competition'. Marketing Science (forthcoming).

Mulhern, F. J. \& Leone, R. P. (1991). 'Implicit Price Bundling of Retail Products: A Multiproduct Approach to Maximizing Store Profitability'. Journal of Marketing, 55 (October): 63-76.

Neslin, S. A. (2002). Sales Promotion, Marketing Science Institute: Cambridge, MA.

Raghubir, P. (2004). 'Coupons in Context: Discounting Prices or Decreasing Profits?' Journal of Retailing, 80 (1): 1-12.

Retail Industry Report (2000) 'At What Price? Guidelines for a Customer-Focused Pricing Strategy'. Arthur Andersen, Report 1, No. 14.

Retail Systems Alert (2003). 'Northern Group Increases Gross Margin via Markdown Optimization'. (January 1).

Sethuraman, R. \& Tellis, G. (2002). 'Does Manufacturer Advertising Suppress or Stimulate Retail Price Promotions? Analytical Model and Empirical Analysis'. Journal of Retailing, 78 (4): 253-263.

Shaffer, G. \& Zhang, J. (1995). 'Competitive Coupon Targeting'. Marketing Science, 14 (4): 395-416.

Shankar, V. \& Bolton, R. N. (2004). 'An Empirical Analysis of Determinants of Retailer Pricing Strategy'. Marketing Science, 23 (1): 28-49.

Srivastava, J. \& Lurie, N. 'Price-Matching Guarantees as Signals of Low Store Prices: Survey and Experimental Evidence',
Journal of Retailing (forthcoming).

Stores (2002). 'Retailers Slow to Adopt Analytics Software.'. 84 (6): 22.

Stremersch, S. \& Tellis, G. J. (2002). 'Strategic Bundling of Products and Prices: A New Synthesis for Marketing'. Journal of Marketing, 66 (January): 55-72.

Tellis, G.J. \& Zufryden, F. F. (1995). 'Tackling the Retailer Decision Maze: Which Brands to Discount, How Much, When, and Why?' Marketing Science, 14 (Summer): 271-299.

Top of the Net (2002). 'Anchors Away for Markdown Solution at Old Navy' (November 4).

Urbany, J. E., Bearden, W. O. \& Weilbaker, D. C. (1988). 'The Effects of Plausible and Exaggerated Reference Prices on Consumer Perceptions and Price Search'. Journal of Consumer Research, 15 (1): 95110.

Walters, R. G. (1991). 'Assessing the Impact of Retail Price Promotions on Product Substitution, Complementary Purchase, and Interstore Sales Displacement'. Journal of Marketing, 55 (April): 17-28.

Winer, R. S. (1986). 'A Reference Price Model of Brand Choice for Frequently Purchased Products'. Journal of Consumer Research, 13 (2): 250-256.

Zenor, M. J. (1994). 'The Profit Benefits of Category Management'. Journal of Marketing Research, 31 (May): 202-213. 